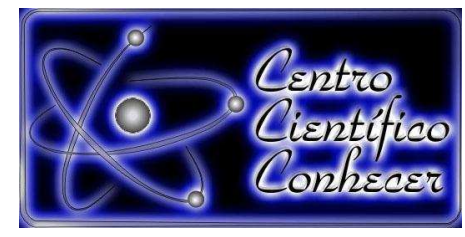

\title{
PRODUTIVIDADE DA Brachiaria brizantha cv. MARANDU EM FUNÇÃO DA ADUBAÇÃO NITROGENADA NA AMAZÔNIA OCIDENTAL
}

\author{
Cleidson Alves da Silva ${ }^{1}$; Bruna Firmino Enck ${ }^{1}$; Jhonny Kelvin Dias Martins ${ }^{2}$; Silvana \\ Ramlow Otto Teixeira da Luz ${ }^{1}$ \\ ${ }^{1}$ Graduado (a) em Agronomia, Fundação Universidade Federal de Rondônia - UNIR, \\ (cleydson91@gmail.com) Rolim de Moura, RO, Brasil \\ ${ }^{2}$ Graduando (a) do curso de Agronomia, Fundação Universidade Federal de \\ Rondônia - UNIR, Rolim de Moura, RO, Brasil
}

Recebido em: 30/11/2017 - Aprovado em: 15/12/2017 - Publicado em: 31/12/2017 DOI: 10.18677/Agrarian Academy 2017b22

\begin{abstract}
RESUMO
O objetivo do trabalho foi avaliar a resposta do capim-marandu quanto à produção de forragem em função à aplicação de diferentes fontes e doses de nitrogênio na região de Rondônia. O experimento foi conduzido em casa-de-vegetação na área experimental da Universidade Federal de Rondônia - UNIR. O delineamento experimental utilizado foi inteiramente cazualizados, em esquema fatorial $2 \times 5$, com quatro repetições, sendo o fator um, fontes de nitrogênio (Sulfato de Amônio e Uréia), e o fator dois, doses de Nitrogênio $\left(0,50,100,150,200 \mathrm{mg} \cdot \mathrm{dm}^{-3}\right)$. Foram realizados dois cortes da planta forrageira, o primeiro 30 dias após a aplicação dos fertilizantes nitrogenados, o segundo 30 dias após o primeiro, sendo cortado de $0,20 \mathrm{~m}$ da superfície do solo. Posteriormente foi mensurada a matéria verde e seca por vaso, e a altura foi mensurada anteriormente cada corte, e o número de perfilhos uma única vez durante o experimento. O sulfato de amônio é superior a uréia para a produção de matéria verde e seca do primeiro e segundo corte. A altura e número de perfilhos é crescente com a aplicação de ambas as fontes para o intervalo de 50 a $200 \mathrm{mg} \cdot \mathrm{dm}^{-3}$ avaliados. Para as condições do experimento o sulfato de amônio é superior a uréia para produtividade de forragem.
\end{abstract}

PALAVRAS-CHAVE: Forragem, Nitrogênio, Produção.

\section{PRODUCTIVITY OF Brachiaria brizantha cv. MARANDU IN THE FUNCTION OF NITROGEN FERTILIZATION IN THE WESTERN AMAZON}

\footnotetext{
ABSTRACT

The objective of this work was to evaluate the response of the marandu grass to the forage production due to the application of different sources and nitrogen doses in the region of Rondônia. The experiment was conducted in greenhouse at the AGRARIAN ACADEMY, Centro Científico Conhecer - Goiânia, v.4, n.8; p.210 2017
} 
experimental area of the Federal University of Rondônia - UNIR. The experimental design was completely randomized, in a $2 \times 5$ factorial scheme, with four replications, being factor one, nitrogen sources (Ammonium Sulphate and Urea) and factor two, Nitrogen doses $(0,50,100,150,200 \mathrm{mg} . \mathrm{dm}-3)$. Two cuts of the forage plant were made, the first thirty days after the application of the nitrogen fertilizers, the second thirty days after the first one, being cut of $0,20 \mathrm{~m}$ of the surface of the soil. Subsequently, the green matter and dry matter per pot were measured, and the height was measured previously each cut, and the number of tillers a single time during the experiment. The ammonium sulphate is superior to urea for the production of green matter and dry of the first and second cut. The height and number of tillers is increasing with the application of both sources for the range of 50 to $200 \mathrm{mg} \cdot \mathrm{dm}^{-3}$ evaluated. For the conditions of the experiment, ammonium sulphate is superior to urea for forage yield.

KEYWORDS: Nitrogen, Production, Forage.

\section{INTRODUÇÃO}

A produção de bovinos para abate caracteriza-se como um dos setores mais importantes do agronegócio brasileiro e consequentemente para economia do País, possui o maior rebanho comercial do mundo, é o maior exportador de carne bovina, segundo maior produtor de carne e sexto maior produtor de leite (USDA, 2014). No entanto, a demanda por produtos cárneos tem aumentado gradativamente, em consequência do aumento da população e com a elevação progressiva da renda "per capita" de países emergentes como o Brasil, China, Índia e Rússia, havendo necessidade de adoção de tecnologias que possibilitem maior produtividade (HOFFMANN et al., 2014).

Martha jr. et al. (2012) citam que a intensificação do sistema alimentar de ruminantes a pasto pode gerar benefícios, incrementando sua capacidade produtiva com maior eficiência dos pastos tropicais. No entanto, as restrições crescentes para a limpeza de novas áreas para o gado geram a demanda de forragens com alta produção de biomassa em resposta a fatores de produção, especialmente a fertilidade do solo, que é o mais manipulável pelo homem (LOPES et al., 2013).

Neste contexto, a aplicação de fertilizantes em áreas de pastagens é uma forma de fornecer os nutrientes para atender as necessidades metabólicas e promover o melhor desenvolvimento das forrageiras, em especial a adubação nitrogenada, sendo fundamental para o aumento da produção de biomassa (SILVA et al., 2013). Dessa forma, estratégias de manejo da pastagem, como a adubação nitrogenada, são muito importantes, porque podem ajudar a oferecer ao animal uma estrutura de dossel que possa otimizar as ações de manejo da forrageira (CARVALHO et al., 2000).

De acordo com Barbero et al. (2009), os fertilizantes nitrogenados são importantes para o desenvolvimento e produção das forrageiras. O nitrogênio é o principal constituinte das proteínas que participam ativamente na síntese dos compostos orgânicos que formam a estrutura do vegetal, com elevada influencia sobre as características morfogênicas e estruturais das plantas (COSTA et al., 2006).

Cerca de $80 \%$ das áreas de pastagens cultivadas no Brasil são ocupadas por genótipos de Brachiaria, como a Brachiaria brizantha cv. Marandu (capim-Marandu) representando 50\% deste total (CARDOSO et al., 2015). Entre outras características 
desta espécie de forragem, como boa cobertura do solo, resistente as cigarrinhas típicas de pastagens, é também considerada de fácil estabelecimento e tem alta resposta à aplicação de fertilizantes (CYPRIANO et al., 2012).

No entanto, são necessárias novas informações para a aplicação adequada da adubação nitrogenada no estabelecimento da Brachiaria brizantha cv. Marandu nas condições edafoclimáticas da Amazônia Ocidental. Neste sentido, objetivou-se avaliar a resposta do capim-marandu quanto à produção de forragem em função à aplicação de diferentes fontes e doses de nitrogênio na região de Rondônia.

\section{MATERIAL E MÉTODOS}

O experimento foi conduzido em casa-de-vegetação na área experimental da Universidade Federal de Rondônia - UNIR, localizada na rodovia 184, km 15, em

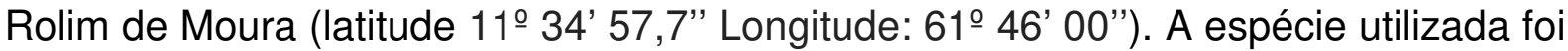
a Brachiaria brizantha cv. Marandu.. O clima conforme a classificação de Köppen é do tipo Aw, que se caracteriza como um clima equatorial com variação para o quente e úmido, com estação seca bem definida (junho a setembro), temperatura mínima de $24^{\circ} \mathrm{C}$, máxima $32^{\circ} \mathrm{C}$, com precipitação anual média de $2.250 \mathrm{~mm} \mathrm{ano}^{-1}$, e com umidade relativa do ar alta, em torno de $85 \%$.

O solo utilizado no experimento foi classificado como Latossolo Vermelho Amarelo, apresentando as seguintes propriedades químicas: $\mathrm{pH}\left(\mathrm{H}_{2} \mathrm{O}\right)=6,44$; M.O.= 8,36 $\left(\mathrm{g} \mathrm{dm}^{-3}\right) ; \mathrm{P}=1,11\left(\mathrm{mg} \mathrm{dm}^{-3}\right) ; \mathrm{K}^{+}=0,02\left(\mathrm{Cmol}_{\mathrm{c}} \mathrm{dm}^{-3}\right) ; \mathrm{Ca}^{+2}=0,88\left(\mathrm{Cmol}_{\mathrm{c}} \mathrm{dm}^{-3}\right)$; $\mathrm{Mg}^{+2}=0,64\left(\mathrm{Cmol}_{\mathrm{c}} \mathrm{dm}^{-3}\right) ; \mathrm{H}^{+}+\mathrm{Al}^{+3}=3,63\left(\mathrm{Cmol}_{\mathrm{c}} \mathrm{dm}^{-3}\right) ; \mathrm{Al}^{+3}=0,00 ;$ Argila $=210(\mathrm{~g}$ $\mathrm{kg}^{-1}$ ). O solo foi coletado na camada arável a uma profundidade de $0-20 \mathrm{~cm}$, e logo em seguido foi posto para secar ao ar, homogeneizado, peneirado e colocado nos vasos com capacidade para seis $\mathrm{kg}$.

$O$ delineamento experimental utilizado foi inteiramente cazualizados, em esquema fatorial $2 \times 5$, com quatro repetições, sendo o fator um, fontes de nitrogênio (Sulfato de Amônio e Uréia), e o fator dois, doses de Nitrogênio $(0,50,100,150,200$ $\mathrm{mg} \cdot \mathrm{dm}^{-3}$ ), parceladas em duas vezes; a primeira após a emergência das plântulas e a segunda coincidindo com o primeiro corte das plantas. Realizou-se adubação básica com superfosfato triplo $\left(55 \mathrm{mg} \cdot \mathrm{dm}^{-3}\right.$ de $\left.\mathrm{P}_{2} \mathrm{O}_{5}\right)$ no início do experimento, e cloreto de potássio $\left(15 \mathrm{mg} \cdot \mathrm{dm}^{-3}\right.$ de $\mathrm{K}_{2} \mathrm{O}$ ) depois da emergência das plântulas.

A semeadura foi realizada utilizando-se aproximadamente 30 sementes por vaso. Após a emergência das plântulas foram realizados desbastes periódicos até permanecerem cinco plantas por vaso. O critério utilizado foi a uniformidade de tamanho entre as mesmas e o vigor vegetativo. O controle hídrico foi realizado duas vezes ao dia, com irrigação manual, tendo como critério a pesagem dos vasos.

Foram realizados dois cortes da planta forrageira. O primeiro trinta dias após a aplicação dos fertilizantes nitrogenados, o segundo trinta dias após o primeiro, sendo cortado de $0,20 \mathrm{~m}$ da superfície do solo. O material vegetal resultante dos cortes avaliativos foi separado para avaliação de matéria verde $\left(\right.$ g.vaso $\left.^{-1}\right)$, pesado logo após o corte, e após foi colocado para secar em estufa de ventilação forçada a $65^{\circ} \mathrm{C}$ por 72 horas para a determinação da matéria seca $\left(\right.$ g.vaso $\left.{ }^{-1}\right)$. A altura da planta $(\mathrm{cm})$ foi avaliada antes de cada corte, e o número de perfilhos $\left(\mathrm{n}^{\circ}\right.$. vaso $\left.{ }^{-1}\right)$ avaliado uma única vez anteriormente ao segundo corte.

Os dados foram submetidos à análise de variância pelo teste $F(p \leq 0,05)$, sendo os resultados significativos foi realizada a comparação de médias, utilizandose 0 teste de Tukey ao nível de $5 \%$ de probabilidade. Para variáveis quantitativas, ajustadas equações de regressão. Todas as variáveis receberam o tratamento 
estatístico utilizando-se o programa computacional Assistat (SILVA ; AZEVEDO, 2002).

\section{RESULTADOS E DISCUSSÃO}

Não houve efeito significativo da interação das fontes de nitrogênio e as doses utilizadas para nenhuma das variáveis analisadas. Para as fontes de nitrogênio houve efeito significativo para massa verde e seca do primeiro e segundo corte. As doses utilizadas se diferiram estatisticamente para as todas as variáveis analisadas (Tabela 1).

TABELA 1. Resumo da análise de variância para as variáveis: Altura (ALT.), Matéria fresca (MF), Matéria seca (MS), do primeiro e segundo corte, e número de perfilhos (NP), submetidas a diferentes fontes e doses de nitrogênio.

\begin{tabular}{|c|c|c|c|c|c|c|c|c|}
\hline \multirow{3}{*}{ FV } & \multirow{3}{*}{ GL } & \multicolumn{7}{|c|}{ Quadrados médios } \\
\hline & & ALT. & MV & MS & ALT. & MV & MS & NP \\
\hline & & \multicolumn{3}{|c|}{ Primeiro corte } & \multicolumn{3}{|c|}{ Segundo corte } & \\
\hline Fonte (F) & 1 & $211,6_{\star \star}^{\text {ns }}$ & $158,7_{\star \star *}^{* *}$ & $22,7_{\star \star \star *}^{* \pi}$ & $11,0^{\mathrm{ns}}$ & $748,1_{\star \star *}^{*}$ & $106,4 *$ & $22,5^{\mathrm{ns}}$ \\
\hline Doses (D) & 4 & $359,3^{\star *}$ & $530,7^{\star *}$ & $76,3^{* *}$ & $74,6^{*}$ & $505,4^{* *}$ & $72,7^{\star \star}$ & $471,3^{\star \star}$ \\
\hline$F \times D$ & 4 & $58,6^{\mathrm{ns}}$ & $37,8^{\text {ns }}$ & $5,4^{\mathrm{ns}}$ & $41,8^{\mathrm{ns}}$ & $34,1^{\mathrm{ns}}$ & $5,23^{\mathrm{ns}}$ & $7,06^{\mathrm{ns}}$ \\
\hline Resíduo & 30 & 63,5 & 14,1 & 2,0 & 67,7 & 18,9 & 2,8 & 9,6 \\
\hline CV (\%) & -- & 11,55 & 17,98 & 18,32 & 9,64 & 12,26 & 12,69 & 16,14 \\
\hline
\end{tabular}

Para as fontes de nitrogênio utilizadas, o sulfato de amônio foi superior a uréia em $17,40 \%$ e $17,53 \%$ quando observados a massa fresca e seca do primeiro corte respectivamente. Comportamento semelhante ocorreu quando comparadas as médias do segundo corte, tendo superioridade do sulfato de amônio em relação a uréia de $21,74 \%$ e 21,82\% para a massa fresca e seca respectivamente (Tabela 2).

TABELA 2 - Sulfato de amônio e uréia sobre a altura de plantas do capim Marandu.

\begin{tabular}{|c|c|c|c|c|}
\hline \multirow{3}{*}{ Fontes } & Matéria verde & Matéria seca & Matéria verde & Matéria seca \\
\hline & Primei & corte & \multicolumn{2}{|c|}{ Segundo corte } \\
\hline & \multicolumn{4}{|c|}{ 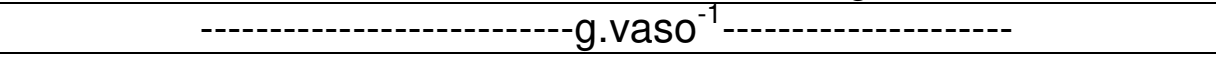 } \\
\hline Sulf. de Amônio & 22,93 a & $8,61 \mathrm{a}$ & 39,78 a & $14,94 \mathrm{a}$ \\
\hline Uréia & $18,94 \mathrm{~b}$ & $7,10 \mathrm{~b}$ & $31,13 \mathrm{~b}$ & $11,68 \mathrm{~b}$ \\
\hline DMS & 2,43 & 0,93 & 2,81 & 1,09 \\
\hline
\end{tabular}

Médias seguidas pela mesma letra na coluna, não diferem entre si, pelo teste Tukey ao nível de $5 \%$ de probabilidade.

Teixeira et al. (2015) avaliando a produtividade da brachiaria cv. Marandu submetida a doses crescentes de uréia e sulfato de amônio, observaram resultados semelhantes, em que o sulfato de amônio foi superior a uréia em $984 \mathrm{~kg} \cdot \mathrm{ha}^{-1}$ de massa verde, o que corresponde a $12,28 \%$ de incremento nesta variável. Costa et al. (2010) observaram também a superioridade de $18 \%$ na produção de massa seca do capim marandu com aplicação da fonte sulfato de amônio comparativamente a aplicação de uréia. Resultados semelhantes também foram encontrados por Silva et al. (2013), em que a fonte sulfato de amônio proporcionou aumento na massa seca 
das lâminas foliares de 0,$9 ; 10 ; 25 \%$ nas doses de 100, 200, $300 \mathrm{~kg} \mathrm{ha}^{-1} \mathrm{ano}^{-1}$, quando comparado à uréia.

De acordo com Silva et al. (2011), a maior produção de massa seca de folhas com a utilização do sulfato de amônio ocorre devido às menores perdas de $\mathrm{N}$, enquanto que, com a utilização da uréia essas perdas de amônia para a atmosfera são mais acentuadas, promovendo menor eficiência da adubação nitrogenada e diminuindo a resposta da planta em produção por unidade de $\mathrm{N}$ aplicado. Esta menor eficiência de uréia é explicada em função das transformações desta no solo, perdendo-se para a atmosfera na forma de $\mathrm{NH}^{3}$ e $\mathrm{N}_{2} \mathrm{O}$ (MARTHA JÚNIOR et al., 2004).

Outro ponto importante que pode ter contribuído para as maiores produções de massa verde e seca na fonte sulfato de amônio é a presença de enxofre, que de acordo com Bonfim-silva e Monteiro (2006), áreas que recebem grandes quantidades de adubo nitrogenado, faz-se necessário o suprimento de enxofre para máximas produções, devido à correlação da quantidade de nitrogênio e enxofre aplicados, que de maneira geral estão entre 10:1.

Para a variável altura, não houve efeito significativo das fontes de nitrogênio, no entanto para o fator doses houve efeito linear tanto para a altura do primeiro e segundo corte. Na maior dose aplicada para altura do primeiro corte obteve-se 15 $\mathrm{cm}$ de incremento relativamente a não aplicação de nitrogênio (Figura 1A). Para 0 segundo corte este incremento foi de $7,5 \mathrm{~cm}$ (Figura 1B).
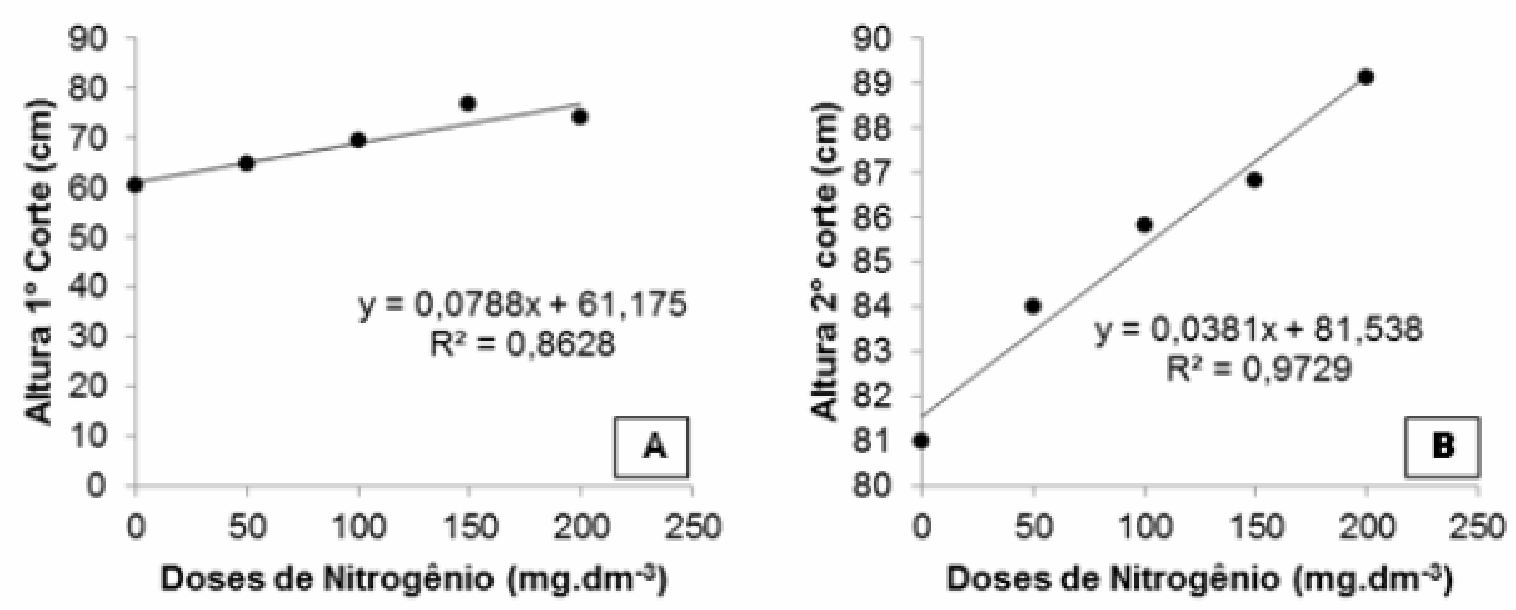

FIGURA 1 - Altura de plantas do primeiro (A) e segundo corte (B) do capim-marandu em função das doses de nitrogênio.

Silva et al. (2013) observaram diferenças significativas para a altura do capim marandu em relação as fontes utilizadas, também que doses crescentes tanto de sulfato de amônio como ureia resultaram em maiores alturas do capim marandu em todos os anos de avaliação $(2004,2005,2006)$, o que corresponde a $129 \%$ de aumento para a fonte sulfato de amônio e $96 \%$ para a uréia, ambas em relação a testemunha sem aplicação de nitrogênio.

De acordo com Cabral et al. (2012), O aumento no tamanho de lâmina em relação aos tratamentos pode ser explicado pelo efeito simultâneo do $\mathrm{N}$, que aumenta de forma expressiva o número de células em processo de divisão, definindo maior comprimento da bainha que a lâmina em expansão terá que percorrer, sendo assim, o nitrogênio, ao estimular a produção de novas células, AGRARIAN ACADEMY, Centro Científico Conhecer - Goiânia, v.4, n.8; p.214 2017 
possibilita aumento na taxa de alongamento de folhas, o que pode constituir meio para mudanças no tamanho da lâmina foliar.

Para a massa verde e seca do primeiro e segundo corte foram feitos ajustes lineares para as doses de nitrogênio aplicadas. Em relação ao tratamento sem a aplicação de nitrogênio, a maior dose obteve-se 180 e 75,2\% de aumento de matéria verde do primeiro e segundo corte respectivamente, assim como houve aumento de matéria seca de $183 \%$ e $76,3 \%$ em relação à testemunha, para o primeiro e segundo corte respectivamente (Figura 2).
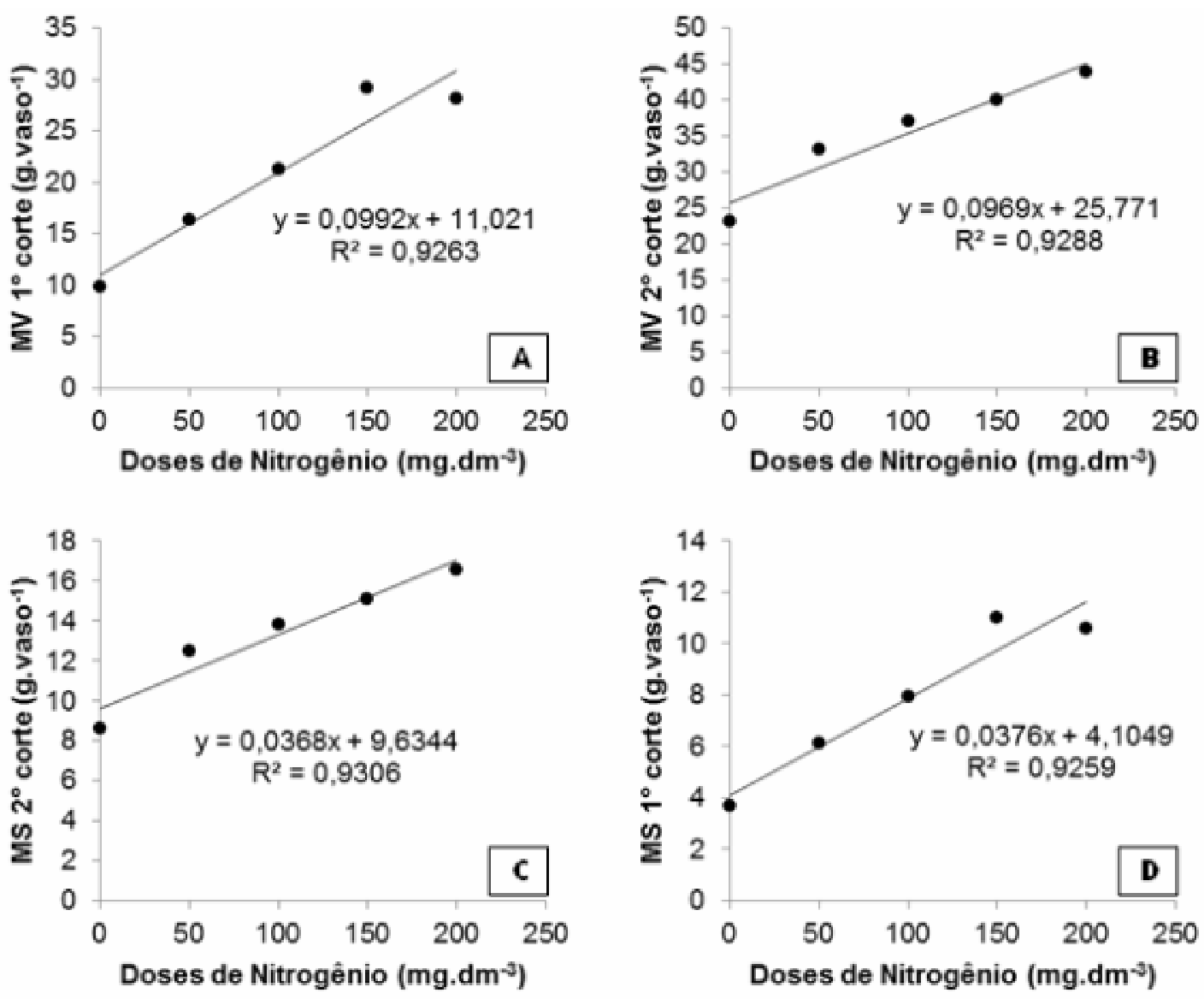

FIGURA 2 - Matéria verde do primeiro corte (A), Matéria verde do segundo corte (B), Matéria seca do primeiro corte (D) e Matéria seca do segundo corte $(C)$ do capim-marandu em função das doses de nitrogênio.

A cada $50 \mathrm{mg} \cdot \mathrm{dm}^{-3}$ de Nitrogênio aplicado houve incremento de 4,85 e $4,96 \mathrm{~g}$. vaso $^{-1}$ de massa verde para o primeiro e segundo corte respectivamente. Para a massa seca, este incremento foi de 1,88 e $1,84 \mathrm{~g} \cdot \mathrm{vaso}^{-1}$ para cada $50 \mathrm{mg} \cdot \mathrm{dm}^{-3}$ aplicados, resultados que reforça 0 indicativo da importância da adubação nitrogenada para a produtividade do capim marandu na Amazônia Sul Ocidental.

Vieira (2014) observou resultados semelhantes, em que a adubação nitrogenada crescente proporcionou maior disponibilidade de matéria seca total do capim marandu até a dose aproximada de $303 \mathrm{~kg}$ de N.ha ${ }^{-1}$. Sales et al. (2013) observaram resultados semelhantes utilizando as mesmas doses de 100, 200, $300 \mathrm{e}$ $400 \mathrm{~kg}$ de N.ha-1, em que o aumento da matéria seca deu-se de forma linear em relação as doses de nitrogênio avaliadas.

A maior produtividades de massa seca e verde se deve pela importância do AGRARIAN ACADEMY, Centro Científico Conhecer - Goiânia, v.4, n.8; p.215 2017 
nitrogênio $(\mathrm{N})$ no crescimento da planta. $\mathrm{O} N$ é constituinte estrutural de moléculas de proteínas, aminoácidos, enzimas, coenzimas, vitaminas e pigmentos, além de atuar diretamente no processo de fotossíntese por meio da participação na molécula de clorofila, tornando-se indispensável para a nutrição de plantas (ALEXANDRINO et al., 2010).

O número de perfilhos por vaso, assim como para as demais variáveis analisadas, teve comportamento linear com as doses de nitrogênio aplicadas (Figura 3). Na maior dose aplicada $\left(200 \mathrm{mg} \cdot \mathrm{dm}^{-3}\right)$ obteve-se aproximadamente 28 perfilhos por vaso, o que significa $211 \%$ de aumento nesta variável em comparação a não aplicação de nitrogênio.

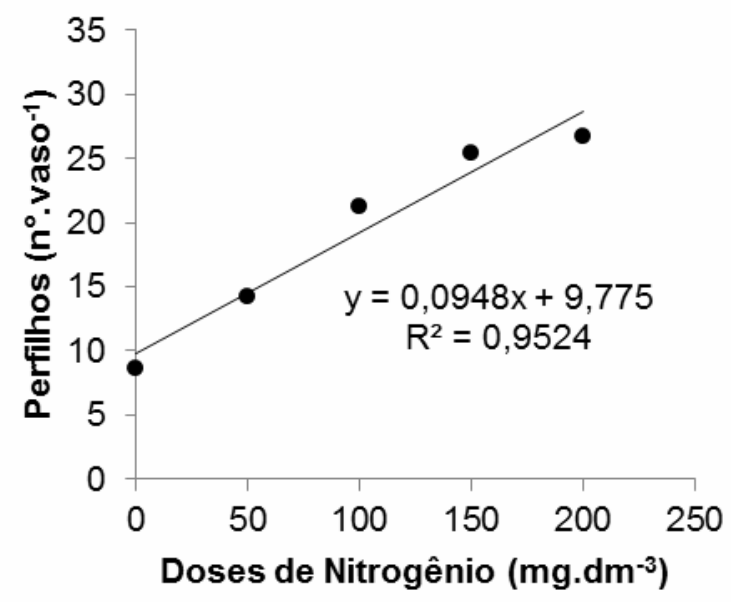

FIGURA 3 - Número de perfilhos por vaso do capim-marandu em função das doses de nitrogênio.

Silva et al. (2013) obtiveram resultados semelhantes com a aplicação de doses de nitrogênio no capim marandu, em que os valores mais elevados para densidade de perfilhos ocorreram na dose de $300 \mathrm{~kg} \mathrm{ha}^{-1} \mathrm{ano}^{-1}$, mostrando aumento em relação a não aplicação de nitrogênio de 109; 122 e 114\% para os anos avaliados de 2004; 2005 e 2006, respectivamente.

O comportamento linear positivo para o número de perfilhos em função das doses crescentes de nitrogênio, assim como para as variáveis: matéria verde e seca, deve-se ao papel importante deste nutriente no crescimento das forrageiras, porque faz parte das proteínas e ácidos nucléicos, os quais participam ativamente da síntese de compostos orgânicos, que formam a estrutura do vegetal (MALAVOLTA, 2006), sendo que a ausência desse nutriente impede o aparecimento de novos perfilhos (PEREIRA et al., 2010).

\section{CONCLUSÕES}

O sulfato de amônio é superior a uréia para as condições edafoclimáticas do local de experimento, produzindo maior produtividade de forragem do capimmarandu. O número de perfilhos é crescente com a aplicação de ambas as fontes para o intervalo de 50 a $200 \mathrm{mg} \cdot \mathrm{dm}^{-3}$. 


\section{REFERÊNCIAS}

ALEXANDRINO, E.; VAZ, R. G. M. V.; SANTOS , A. C. Características da Brachiaria brizantha $\mathrm{cv}$. marandu durante o seu estabelecimento submetida a diferentes doses de nitrogênio. Revista Biosciencie Journal., v. 26, n. 6, p. 886-893, 2010.

BARBERO, L. M.; CECATO, U.; LUGÃO, S. M. B.; GOMES, J. A. N.; LIMÃO, V. A.; BASSO, K. C. Produção de forragem e componentes morfológicos em pastagem de coastcross consorciada com amendoim forrageiro. Revista Brasileira de Zootecnia, v. 38, n. 5, p. 788-795, 2009. Disponível em: <http://dx.doi.org/10.1590/S151635982009000500002>. DOI: 10.1590/S1516-35982009000500002

BONFIM-SILVA, E. M.; MONTEIRO, F. A. Nitrogênio e enxofre em características produtivas do capim-braquiária proveniente de área de pastagem em degradação. Revista Brasileira de Zootecnia, v. 35, n. 04, p. 1289-1297, 2006. Disponível em: <http://dx.doi.org/10.1590/S1516-35982006000500006>. DOI: $10.1590 / S 1516$ 35982006000500006

CABRAL, W. B.; SOUZA, A. L.; ALEXANDRINO, E.; TORAL, F. L. B.; SANTOS, J. N.; CARVALHO, M. V. P. Características estruturais e agronômicas da Brachiaria brizantha Cv. Xaraés submetida a doses de nitrogênio. Revista Brasileira de Zootecnia, Viçosa, v. 41, n. 4, p. 846-855, 2012. Disponível em: <http://dx.doi.org/10.1590/S1516-35982012000400004>. DOI: 10.1590/S151635982012000400004

CARDOSO, J. M. S.; ANDRADE, A. C.; MAGALHÃES, J. A.; RODRIGUES, B. H. N.; VIEIRA, J. S.; FOGAÇA, F. H. S.; MEHL, H. U.; COSTA, N. L. Fontes e doses de nitrogênio na produtividade do capim-Marandu. Publicações em Medicina Veterinária e Zootecnia, v. 9, n. 8, p. 348-358, 2015.

CARVALHO, C. A. B.; SILVA, S. C.; CARNEVALLI, R.A.; SBRISSIA, A. F.; PINTO, L. F. M.; FAGUNDES, J. L.; PEDREIRA, C. G. S. Perfilhamento e acúmulo de forragem em pastagens de Florakirk (Cynodon spp.) sob pastejo. Boletim da Indústria Animal, v. 57, n. 01, p. 39-51, 2000.

COSTA, K.A.P.; FAQUIN, V.; OLIVEIRA, I.P. Doses e fontes de nitrogênio na recuperação de pastagens do capim-marandu. Arquivo Brasileiro de Medicina Veterinária e Zootecnica, v.62, n.1, p.192-199, 2010. Disponível em: <http://dx.doi.org/10.1590/S0102-09352010000100026>. DOI: 10.1590/S010209352010000100026

COSTA, N.L., PAULINO, V.T.; MAGALHÃES, J.A. Produção de forragem, composição química e morfogênese de Panicum maximum cv. Vencedor sob diferentes níveis de adubação nitrogenada. Revista Científica de Produção Animal, v.8, p. 66-72, 2006. Disponível em: <https://doi.org/10.15528/407>. DOI: $10.15528 / 407$

CYPRIANO, M. P.; REIS, G.; HORTA, L. F.; SOARES, M. P. Variedades de pastagens. 2012, (Informativo Técnico). 
HOFFMANN, A.; MORAES, E. H. B. K.; MOUSQUER, C. J.; SIMIONI, T. A.; JUNIOR GOMES, F.; FERREIRA, V. B.; SILVA, H. M. Produção de bovinos de corte no sistema de pasto-suplemento no período seco. Nativa, v. 02, n. 02, p. 119-130, 2014. Disponível em: <http://dx.doi.org/10.14583/2318-7670.v02n02a10>. DOI: 10.14583/2318-7670.v02n02a10

LOPES, M.N.; CANDIDO, M.J.D.; POMPEU, R.C.F.F.; SILVA, R. G.; CARVALHO, T. C. F.; SOMBRA, W. A.; NETO, L. B. M.; PEIXOTO, M. J. A. Biomass flow in massai grass fertilized with nitrogen under intermittent stocking grazing with sheep. Revista Brasileira de Zootecnia, v.42, n.1, p.13-21, 2013. Disponível em: <http://dx.doi.org/10.1590/S1516-35982013000100003>. DOI: $10.1590 / S 1516-$ 35982013000100003

MALAVOLTA, E. Manual de nutrição mineral de plantas. São Paulo: Ceres, 2006. $638 \mathrm{p}$.

MARTHA JR., G. B.; ALVES, E.; CONTINI, E. Land-saving approaches and beef production growth in Brazil. Agricultural Systems, v. 110, p. 173-177, 2012. Disponível em: <https://doi.org/10.1016/j.agsy.2012.03.001>. DOI: 10.1016/j.agsy.2012.03.001

MARTHA JÚNIOR, G. B.; CORSI, M.; TRIVELIN, P. C. O.; VILELA, L.; PINTO, T. L. F.; TEIXEIRA, G. A.; MANZONI, C. S.; BARIONI, L. G. Perdas de amônia por volatilização em pastagem de capim-tanzânia adubada com uréia no verão. Revista Brasileira de Zootecnia, v. 33, n. 06, p. 2240-2247, 2004. Disponível em: <http://dx.doi.org/10.1590/S1516-35982004000900009>. DOI: 10.1590/S151635982004000900009

PEREIRA, L. E. T.; PAIVA, A. J.; SILVA, S. C.; CAMINHA, F. O.; GUARDA, V. D. A.; PEREIRA, P. M. Sward structure of marandu palisadegrass subjected to continuous stocking and nitrogen-induced rhythms of growth. Scientia Agricola, v. 67, n. 05, p. 531-539, 2010. Disponível em: <http://dx.doi.org/10.1590/S010390162010000500006>. DOI: 10.1590/S0103-90162010000500006

SALES, E. C. J.; MONÇÃO, F. P.; PEREIRA, D. A.; MOTA, V. A. C.; REIS, S. T.; PIRES. D. A.; ALVES, D. D.; SAMPAIO. J. P. R. Produção de capim-marandu sob doses de nitrogênio em duas alturas de resíduos pós corte. Revista Unimontes Científica, v. 15, n. 2, p. 42-54, 2013.

SILVA, D. R. G.; COSTA, K. A. P.; FAQUIN, V.; OLIVEIRA, I. P.; BERNARDES, T. F. Doses e fontes de nitrogênio na recuperação das características estruturais e produtivas do capim-marandu. Revista Ciência Agronômica, v. 44, n. 1, p. 184191, 2013. Disponível em: <http://dx.doi.org/10.1590/S1806-66902013000100023>. DOI: $10.1590 /$ S1806-66902013000100023

SILVA, D. R. G.; COSTA, K. A. P.; FAQUIN, V.; OLIVEIRA, I. P.; SOUZA, M. R. F.; SOUZA, M. A. S. Eficiência nutricional e aproveitamento do nitrogênio pelo capimmarandu de pastagem em estágio moderado de degradação sob doses e fontes de nitrogênio. Ciência e Agrotecnologia, v. 35, n. 02, p. 242-249, 2011. Disponível em: 
<http://dx.doi.org/10.1590/S1413-70542011000200003>. DOI: 10.1590/S141370542011000200003

SILVA, F. de A. S. E., AZEVEDO, C. A. V. Versão do programa computacional Assistat para o sistema operacional Windows. Revista Brasileira de Produtos Agroindustriais, Campina Grande, v.4, p.71-78, 2002. Disponível em: <http://dx.doi.org/10.15871/1517-8595/rbpa.v4n1p71-78>. DOI: $10.15871 / 1517-$ 8595/rbpa.v4n1p71-78

TEIXEIRA, S. O.; TEIXEIRA, E. E. R.; SANTOS, V. B.; YAMASHITA, O. M.; CARVALHO, M. A. C. Produtividade de braquiárias em função da aplicação de fontes e doses de nitrogênio no início da estação seca. In: SEMINÁRIO DE BIODIVERSIDADE E AGROECOSSISTEMAS AMAZÔNICOS, 3., 2015, Alta Floresta. Anais... Alta Floresta, 2015. p. 484-489, 2015.

USDA. USDA Foreign Agricultural Service. Disponível em <http://apps.fas.usda.gov/psdonline/>. Acesso em setembro de 2014.

VIEIRA, A. J. Efeito da adubação nitrogenada e alturas de manejo sobre a Brachiaria brizantha stapf cv. Marandu. 2014, 62f. Trabalho de Conclusão de Curso (Bacharelado em Zootecnia) - Universidade Federal de Roraima, Boa Vista, 2014. 